\title{
Prevalence of Hepatitis B Virus Infection in Patients with Rheumatic Diseases in Tohoku Area: A Retrospective Multicenter Survey
}

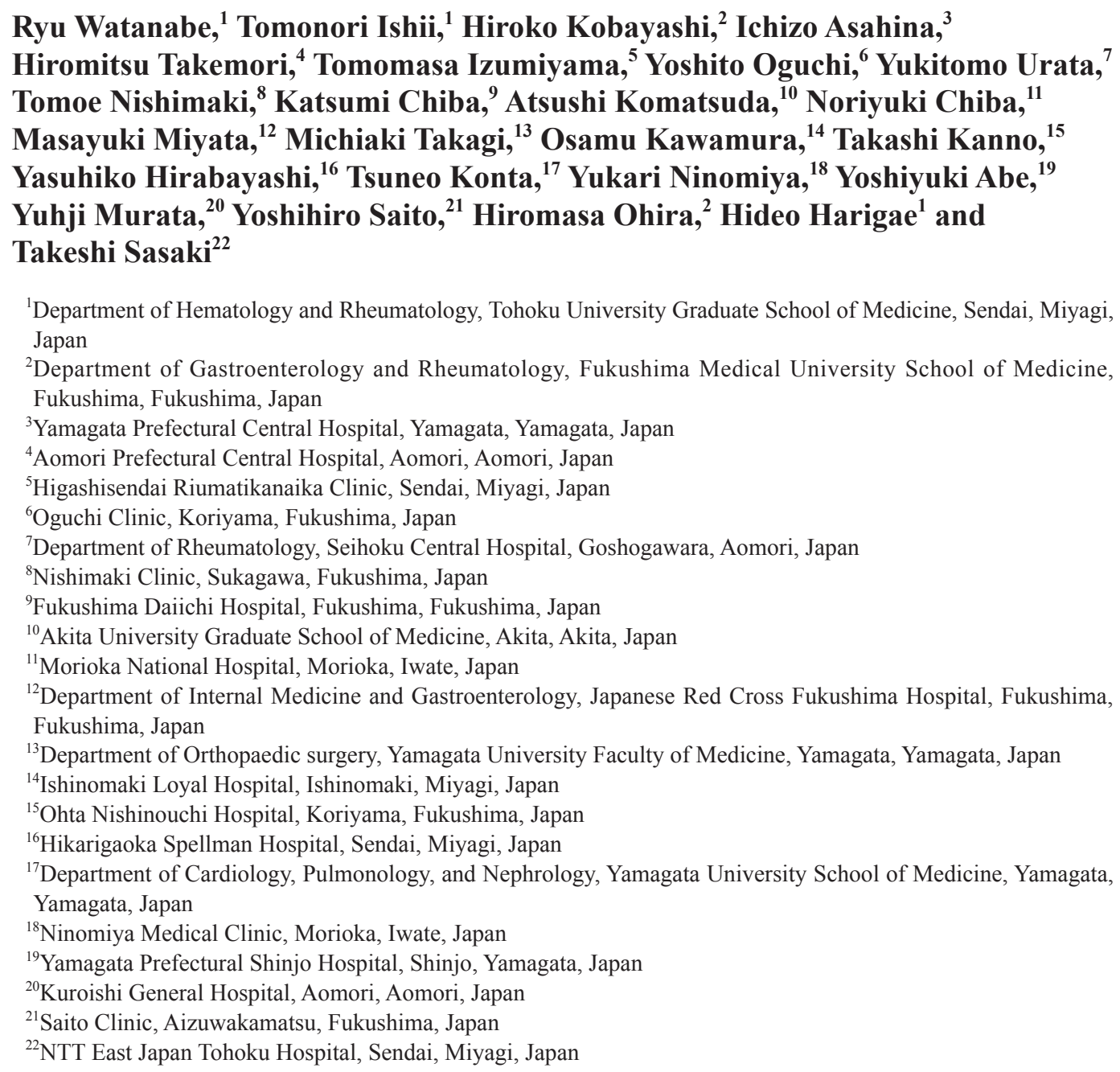

Hepatitis $B$ virus (HBV) reactivation has been increasingly recognized in patients receiving chemotherapy and immunosuppressive therapy; however, the prevalence of HBV infection and rate of HBV screening in patients with rheumatic diseases remains unclear. In this study, we aimed to assess the prevalence of HBV infection and fulminant HBV hepatitis in patients with rheumatic diseases. We also investigated the rate of HBV screening before immunosuppressive therapy in patients with rheumatic diseases. A retrospective questionnaire survey was conducted in the North-east area (Tohoku) of Japan. Questionnaires, comprising 6 questions, were sent to 318 rheumatologists in May 2010, and responses were gathered until June 2011. In total, 71 rheumatologists $(22.3 \%$ ) responded to the survey. We enrolled 7,650 patients with rheumatoid arthritis (RA) and 1,031 patients with systemic lupus erythematosus (SLE). When limited to institutes at which almost all ( $\geq 90 \%)$ patients were tested for HBV serology, $1.1 \%(40 / 3,580)$ patients with RA and $0.3 \%$ $(3 / 1,128)$ patients with SLE were positive for hepatitis B surface antigen (HBsAg), and 25.2\% (177/703) patients with RA and $13.7 \%$ (34/248) patients with SLE were positive for hepatitis B core antibody (HBcAb).

Received March 11, 2014; revised and accepted May 21, 2014. Published online June 4, 2014; doi: 10.1620/tjem.233.129.

Correspondence: Tomonori Ishii, M.D., Ph.D., Department of Hematology and Rheumatology, Tohoku University Graduate School of Medicine, 1-1 Seiryo-machi, Aoba-ku, Sendai, Miyagi 980-8574, Japan.

e-mail: tishii@med.tohoku.ac.jp 
About one-third of rheumatologists did not check HBsAg and more than half did not check hepatitis $B$ surface antibody (HBsAb) or HBcAb at all before therapy. Fulminant HBV hepatitis was observed in $1 \mathrm{RA}$ patient who was current HBV carrier. In conclusion, the prevalence of HBV infection is high in patients with RA and SLE. HBV screening before immunosuppressive therapy should be strictly performed.

Keywords: hepatitis B virus; immunosuppressive therapy; rheumatoid arthritis; screening; systemic lupus erythematosus

Tohoku J. Exp. Med., 2014 June, 233 (2), 129-133. C 2014 Tohoku University Medical Press

\section{Introduction}

After the widespread use of rituximab, an anti-CD20 monoclonal antibody, hepatitis B virus (HBV) reactivation has been increasingly recognized in patients receiving chemotherapy and immunosuppressive therapy (Oketani et al. 2012). Some studies have shown that HBV reactivation occurs not only in 'current HBV carriers', who are positive for hepatitis B surface antigen ( $\mathrm{HBsAg}$ ), but also in 'resolved HBV carriers', who are negative for HBsAg but positive for hepatitis B surface antibody (HBsAb) and/or hepatitis B core antibody (HBcAb) (Oketani et al. 2012). Particularly, HBV reactivation in resolved carriers may often cause a type of fulminant hepatitis, termed as de novo HBV hepatitis, with an extremely high mortality rate (Umemura et al. 2008).

Based on these results, Centers for Disease Control (CDC) recommended screening for HBV serology before chemotherapy and immunosuppressive therapy (Weinbaum et al. 2008). The American College of Rheumatology (ACR) also recommends HBV screening before immunosuppressive therapy (Singh et al. 2012), and recently, the Japanese College of Rheumatology (JCR) proposed an algorithm for HBV screening (Harigai et al. 2014). According to this algorithm, all patients should be screened for $\mathrm{HBsAg}$ before immunosuppressive therapy. In addition, those who are negative for HBsAg should be tested for $\mathrm{HBsAb}$ and $\mathrm{HBcAb}$. HBV DNA quantification by real-time polymerase chain reaction (RT-PCR) should be performed in resolved HBV carriers. When HBV DNA becomes positive during and after therapy, prophylactic nucleoside analogs such as entecavir should be administered (Harigai et al. 2014). However, evidence to support validity of this algorithm to prevent severe hepatitis is not sufficient and especially needs to clarify cost-benefit relations.

HBV is endemic in Japan, and approximately $20 \%$ Japanese individuals are infected with HBV (Kiyosawa et al. 1994). Therefore, HBV screening before treatment should be more strictly performed in Japan than in other non-endemic countries. However, only few studies have reported the prevalence of $\mathrm{HBV}$ infection and rate of $\mathrm{HBV}$ screening in Japanese patients with rheumatic diseases (Urata et al. 2011; Mori 2011; Watanabe et al. 2013)

In this study, we assessed the prevalence of HBV infection and fulminant HBV hepatitis in patients with rheumatic diseases such as rheumatoid arthritis (RA) and systemic lupus erythematosus (SLE). In addition, we investigated the rate of HBV screening before immunosuppressive therapy in patients with rheumatic diseases.

\section{Methods}

A retrospective questionnaire survey was conducted in the North-east area (Tohoku) of Japan. Questionnaires were sent to 318 rheumatologists in May 2010, and we waited for the response until June 2011. Following are the 6 questions listed in the questionnaire: (1) How many patients with RA have you treated? (2) How prevalent is HBV infection in patients with RA? (3) How many patients with SLE have you treated? (4) How prevalent is HBV infection in patients with SLE? (5) Do you examine serological HBV markers before treatment in patients with rheumatic diseases? (6) Have you ever experienced patients with fulminant HBV hepatitis? In this simplified questionnaire survey, we did not check a detail on sex, age, and hepatitis enzymes. We checked each HBV serological marker independently. Therefore, we did not check HBsAg positivity in $\mathrm{HBcAb}$-positive patients.

Diagnoses of RA and SLE were based on RA classification criteria and SLE classification criteria (Arnett et al. 1988; Hochberg 1997; Aletaha et al. 2010). HBV serological tests were performed before starting immunosuppressive therapy at each institute. Immunosuppressive therapy was defined as the use of biologics, immunosuppressive disease-modifying antirheumatic drugs (DMARDs) including methotrexate (MTX), tacrolimus, leflunomide, mizoribine, corticosteroids, and other immunosuppressive agents (Harigai et al. 2014). The study protocol was approved by the ethics committees of Tohoku University Graduate School of Medicine.

\section{Results}

\section{Overall response rate}

Of the 318 rheumatologists, 71 (22.3\%) responded to the questionnaire. Although we waited for the response until June 2011, all the answers obtained were before the Great East-Japan Earthquake (March 11, 2011).

\section{Prevalence of $H B V$ infection in patients with $R A$}

In total, 7,650 patients with RA were enrolled. $0.7 \%$ $(50 / 7,650)$ patients with RA were considered to be current HBV carriers, and $25.6 \%$ (214/837) were positive for $\mathrm{HBcAb}$ (Table 1). When the patient cohort was limited to institutes at which HBV serology was examined for almost all patients $(\geq 90 \%), 1.1 \%(40 / 3,580)$ patients with RA were current HBV carriers, and 25.2\% (177/703) were positive for $\mathrm{HBcAb}$. Among patients receiving biologics, $0.3 \%$ $(3 / 1,128)$ patients were positive for HBsAg, indicating that 
Table 1. Positivity rate for each HBV serological marker in patients with RA.

\begin{tabular}{|c|c|c|c|c|}
\hline & & $\mathrm{HBsAg}$ & $\mathrm{HBsAb}$ & $\mathrm{HBcAb}$ \\
\hline \multirow[t]{2}{*}{ All patients } & Total & $\begin{array}{c}50 / 7,650 \\
(0.7 \%)\end{array}$ & $\begin{array}{c}245 / 1,295 \\
(18.9 \%)\end{array}$ & $\begin{array}{l}214 / 837 \\
(25.6 \%)\end{array}$ \\
\hline & at institutes $\geq 90 \%$ patients were examined & $\begin{array}{c}40 / 3,580 \\
(1.1 \%)\end{array}$ & $\begin{array}{c}169 / 1,011 \\
(16.7 \%)\end{array}$ & $\begin{array}{l}177 / 703 \\
(25.2 \%)\end{array}$ \\
\hline \multirow[t]{2}{*}{ Patients with biologics } & Total & $\begin{array}{l}3 / 1,634 \\
(0.2 \%)\end{array}$ & $\begin{array}{c}68 / 512 \\
(13.3 \%)\end{array}$ & $\begin{array}{r}64 / 274 \\
(23.4 \%)\end{array}$ \\
\hline & at institutes $\geq 90 \%$ patients were examined & $\begin{array}{l}3 / 1,128 \\
(0.3 \%)\end{array}$ & $\begin{array}{c}49 / 391 \\
(12.5 \%)\end{array}$ & $\begin{array}{r}57 / 199 \\
(28.6 \%)\end{array}$ \\
\hline
\end{tabular}

Table 2. Positivity rate for each HBV serological marker in patients with SLE.

\begin{tabular}{lccc}
\hline & HBsAg & HBsAb & HBcAb \\
\hline Total & $3 / 1,031(0.3 \%)$ & $26 / 284(9.2 \%)$ & $38 / 267(14.2 \%)$ \\
at institutes $\geq 90 \%$ patients were examined & $3 / 704(0.4 \%)$ & $25 / 248(10.1 \%)$ & $34 / 248(13.7 \%)$ \\
\hline
\end{tabular}

Table 3. Screening rate for each HBV marker before starting immunosuppressive therapy in 71 rheumatologists.

\begin{tabular}{lcccc}
\hline & HBsAg & HBsAb & HBcAb & HBV DNA \\
\hline All patients & $18(25 \%)$ & $2(3 \%)$ & $4(6 \%)$ & $0(0 \%)$ \\
Not all patients & $30(42 \%)$ & $24(34 \%)$ & $29(41 \%)$ & $21(30 \%)$ \\
None & $23(32 \%)$ & $45(63 \%)$ & $38(54 \%)$ & $50(70 \%)$ \\
\hline Total & 71 & 71 & 71 & 71 \\
\hline
\end{tabular}

biologics tended to be avoided in current HBV carriers. In contrast, biologics were prescribed for resolved HBV carriers at a similar rate to patients without HBV infection.

\section{Prevalence of HBV infection in patients with SLE}

Among 1,031 patients with SLE, 3 patients (0.3\%) were positive for HBsAg (Table 2). When limited to institutes at which $\mathrm{HBV}$ serology was examined for almost all patients ( $\geq 90 \%), 0.4 \%(3 / 704)$ patients were positive for HBsAg and $13.7 \%(34 / 248)$ showed positive results for $\mathrm{HBcAb}$, indicating that the prevalence of $\mathrm{HBV}$ infection in patients with SLE was lower than that in patients with RA ( $p=0.0002$, Chi-square test).

\section{Rate of HBV screening before immunosuppressive therapy}

The rate of screening for HBV serological markers before initiating treatment is summarized in Table 3. 71 rheumatologists answered it with respect to each HBV serological marker. HBsAg was examined for all patients by a relatively high number of clinicians $(18 / 71,25 \%)$; however, approximately one-third clinicians $(23 / 71,32 \%)$ did not check HBsAg at all and more than half of the clinicians did not check $\mathrm{HBsAb}$ or $\mathrm{HBcAb}$ at all.

\section{Fulminant HBV hepatitis}

Among all answers, fulminant HBV hepatitis was reported in 1 patient with RA. This patient was 70's female and current HBV carrier (HBsAg-positive, and hepatitis Be antigen-negative), but was treated by MTX $8 \mathrm{mg} /$ week and prednisolone (PSL) $5 \mathrm{mg} /$ day without nucleoside analogs in general physician's clinic. HBV DNA quantification was not performed in this clinic. The patient was admitted to a nearest university hospital and treated with plasma exchange and entecavir, but died of fulminant HBV hepatitis confirmed by HBV DNA quantification and autopsy.

\section{Discussion}

This retrospective multicenter questionnaire survey conducted in the North-east area of Japan demonstrated that approximately $1 \%$ patients with RA were current HBV carriers and more than $25 \%$ were considered to be resolved carriers. Previous reports in Japan showed similar results estimating that $25 \%(60 / 239)$ patients in Kumamoto and $31.5 \%(135 / 428)$ in Aomori were infected with HBV (Urata et al. 2011; Mori 2011), indicating that more than onefourth patients with RA may be infected with $\mathrm{HBV}$ in Japan. However, the number of patients enrolled in this study is much larger than previous reports. To our knowledge, this is the largest study regarding prevalence of HBV infection in RA patients in Japan. Our data suggest that HBV screening and appropriate management of HBV should be strictly performed when initiating immunosuppressive therapy. Prevalence of HBV infection was significantly lower $(16.5 \%$; $41 / 248)$ in patients with SLE than that in patients with RA (Watanabe et al. 2013). It has been reported that older adults had a higher frequency of HBV 
infection that younger adults in Japan (Tanaka et al. 2011). Therefore, one reason to explain this may be the different ages of onset of RA and SLE. However, because high-dose corticosteroids and intensive immunosuppressive therapy, such as cyclophosphamide, are often required to treat patients with SLE, we should not overlook the risk of HBV reactivation, even in patients with SLE.

This retrospective survey is the first report about the rate of HBV screening before immunosuppressive therapy in Japan and also showed that the rate was low in routine clinical practice. However, previous reports from oncologists showed similar results (Tran et al. 2010; Day et al. 2011a, b; Hwang et al. 2012; Zurawska et al. 2012; Lee et al. 2012). For example, Hwang et al. (2012) reported that among 10,729 patients who received chemotherapy, only 1,787 (16.7\%) underwent screening for HBsAg or HBcAb. As for rheumatologists, Stine et al. (2010) conducted a nationwide questionnaire survey about HBV screening in 1,000 ACR members. Responses obtained (153/1,000, $15.3 \%)$ were highly variable and more than half of the members did not check HBsAb or HBcAb prior to initiating therapy. The authors concluded that it is necessary to improve education among rheumatologists regarding the risks of HBV reactivation in patients in whom immunosuppressive therapy needs to be started.

Recent advances in treatment have changed the therapeutic goal of patients with RA and other rheumatic diseases (Harigai et al. 2014). Biologics, high-dose MTX, and corticosteroids are being increasingly used to induce remission or low disease activity. Among them, the use of biologics, such as tumor necrosis factor- $\alpha$ inhibitors, may cause HBV reactivation (Urata et al. 2011). However, MTX and corticosteroids also have the potential to induce HBV reactivation and de novo hepatitis (Urata et al. 2011; Harigai et al. 2014). The use of biologics is now contraindicated in current HBV carriers (Harigai et al. 2014); however, some rheumatologists prescribe them for current HBV carriers in this study (Table 1). Recently, with an increasing interest in HBV reactivation in Japan, the rate of HBV screening may continue to increase. Nevertheless, a new framework to improve the assessment of the risk of HBV reactivation and fulminant HBV hepatitis by Japanese rheumatologists needs to be developed.

Although fulminant HBV hepatitis was observed in 1 patient who was current carrier, fulminant hepatitis due to HBV reactivation in resolved carriers was not reported in this retrospective study. However, this does not mean that fulminant $\mathrm{HBV}$ hepatitis does not occur in resolved carriers because the rate of HBV screening was low. Therefore, we are now conducting a multicenter prospective study to investigate the rate of HBV reactivation in patients with rheumatic diseases under immunosuppressive therapy.

In conclusion, this retrospective questionnaire study demonstrated that approximately $20 \%$ or more patients with rheumatic diseases were infected with HBV and the rate of HBV screening before immunosuppressive therapy among rheumatologists was low in routine clinical practice. Although the incidence of fulminant HBV hepatitis was low, we rheumatologists should improve our consciousness regarding the risk of $\mathrm{HBV}$ reactivation and management of HBV infection.

\section{Acknowledgments}

We thank all rheumatologists who participated in our retrospective study conducted in the Tohoku area. This study was supported by Ichinohasama Memorial READ Blood Academy.

\section{Conflict of Interest}

The authors declare no conflict of interest.

\section{References}

Aletaha, D., Neogi, T., Silman, A.J., Funovits, J., Felson, D.T., Bingham, C.O. 3rd., Birnbaum, N.S., Burmester, G.R., Bykerk, V.P., Cohen, M.D., Combe, B., Costenbader, K.H., Dougados, M., Emery, P., Ferraccioli, G., et al. (2010) 2010 Rheumatoid arthritis classification criteria: an American College of Rheumatology/European League Against Rheumatism collaborative initiative. Arthritis Rheum., 62, 2569-2581.

Arnett, F.C., Edworthy, S.M., Bloch, D.A., McShane, D.J., Fries, J.F., Cooper, N.S., Healey, L.A., Kaplan, S.R., Liang, M.H., Luthra, H.S., Medsger, T.A., Mitchell, D.M., Neustadt, D.H., Pinals, R.S., Schaller, J.G., et al. (1988) The American Rheumatism Association 1987 revised criteria for the classification of rheumatoid arthritis. Arthritis Rheum., 31, 315-324.

Day, F.L., Karnon, J. \& Rischin, D. (2011a) Cost-effectiveness of universal hepatitis B virus screening in patients beginning chemotherapy for solid tumors. J. Clin. Oncol., 29, 32703277.

Day, F.L., Link, E., Thursky, K. \& Rischin, D. (2011b) Current hepatitis B screening practices and clinical experience of reactivation in patients undergoing chemotherapy for solid tumors: a nationwide survey of medical oncologists. J. Oncol. Pract., 7, 141-147.

Harigai, M., Mochida, S., Mimura, T., Koike, T. \& Miyasaka, N. (2014) A proposal for management of rheumatic disease patients with hepatitis B virus infection receiving immunosuppressive therapy. Mod. Rheumatol., 24, 1-7.

Hochberg, M.C. (1997) Updating the American College of Rheumatology revised criteria for the classification of systemic lupus erythematosus. Arthritis Rheum., 40, 1725.

Hwang, J.P., Fisch, M.J., Zhang, H., Kallen, M.A., Routbort, M.J., Lal, L.S., Vierling, J.M. \& Suarez-Almazor, M.E. (2012) Low rates of hepatitis B virus screening at the onset of chemotherapy. J. Oncol. Pract., 8, e32-39.

Kiyosawa, K., Tanaka, E., Sodeyama, T., Yoshizawa, K., Yabu, K., Furuta, K., Imai, H., Nakano, Y., Usuda, S., Uemura, K., Furuta, S., Watanabe, Y., Watanabe, J., Fukuda, Y. \& Takayama, T.; the South Kiso Hepatitis Study Group (1994) Transmission of hepatitis $\mathrm{C}$ in an isolated area in Japan: community-acquired infection. Gastroenterology, 106, 15961602.

Lee, R.S., Bell, C.M., Singh, J.M. \& Hicks, L.K. (2012) Hepatitis B screening before chemotherapy: a survey of practitioners' knowledge, beliefs, and screening practices. J. Oncol. Pract., 8, 325-328.

Mori, S. (2011) Past hepatitis B virus infection in rheumatoid arthritis patients receiving biological and/or nonbiological disease-modifying antirheumatic drugs. Mod. Rheumatol., 21, 621-627.

Oketani, M., Ido, A., Uto, H. \& Tsubouchi, H. (2012) Prevention of hepatitis B virus reactivation in patients receiving immunosuppressive therapy or chemotherapy. Hepatol. Res., 42, 
627-636.

Singh, J.A., Furst, D.E., Bharat, A., Curtis, J.R., Kavanaugh, A.F., Kremer, J.M., Moreland, L.W., O'Dell, J., Winthrop, K.L., Beukelman, T., Bridges, S.L. Jr., Chatham, W.W., Paulus, H.E., Suarez-Almazor, M., Bombardier, C., et al. (2012) 2012 update of the 2008 American College of Rheumatology recommendations for the use of disease-modifying antirheumatic drugs and biologic agents in the treatment of rheumatoid arthritis. Arthritis Care Res., 64, 625-639.

Stine, J.G., Khokhar, O.S., Charalambopoulos, J., Shanmugam, V.K. \& Lewis, J.H. (2010) Rheumatologists' awareness of and screening practices for hepatitis B virus infection prior to initiating immunomodulatory therapy. Arthritis Care Res., 62, 704-711.

Tanaka, J., Koyama, T., Mizui, M., Uchida, S., Katayama, K., Matsuo, J., Akita, T., Nakashima, A., Miyakawa, Y. \& Yoshizawa, H. (2011) Total numbers of undiagnosed carriers of hepatitis $\mathrm{C}$ and $\mathrm{B}$ viruses in Japan estimated by age- and area-specific prevalence on the national scale. Intervirology, $\mathbf{5 4}, 185-195$.

Tran, T.T., Rakoski, M.O., Martin, P. \& Poordad, F. (2010) Screening for hepatitis B in chemotherapy patients: survey of current oncology practices. Aliment. Pharmacol. Ther., 31,
240-246.

Umemura, T., Tanaka, E., Kiyosawa, K. \& Kumada, H. (2008) Mortality secondary to fulminant hepatic failure in patients with prior resolution of hepatitis B virus infection in Japan. Clin. Infect. Dis., 47, e52-56.

Urata, Y., Uesato, R., Tanaka, D., Kowatari, K., Nitobe, T., Nakamura, Y. \& Motomura, S. (2011) Prevalence of reactivation of hepatitis B virus replication in rheumatoid arthritis patients. Mod. Rheumatol., 21, 16-23.

Watanabe, R., Ishii, T., Nakamura, K., Shirai, T., Tajima, Y., Fujii, H. \& Harigae, H. (2013) Prevalence and time course of hepatitis B virus infection in patients with systemic lupus erythematosus under immunosuppressive therapy. Mod. Rheumatol., 23, 1094-1100.

Weinbaum, C.M., Williams, I., Mast, E.E., Wang, S.A., Finelli, L., Wasley, A., Neitzel, S.M. \& Ward, J.W. (2008) Recommendations for identification and public health management of persons with chronic hepatitis B virus infection. MMWR Recomm. Rep., 57, 1-20.

Zurawska, U., Hicks, L.K., Woo, G., Bell, C.M., Krahn, M., Chan, K.K. \& Feld, J.J. (2012) Hepatitis B virus screening before chemotherapy for lymphoma: a cost-effectiveness analysis. $J$. Clin. Oncol., 30, 3167-3173. 